\title{
Risks Associated with Drug Treatments for Kidney Stones
}

\section{${ }^{1}$ Nadya York, M.D., ${ }^{2}$ Michael S. Borofsky, M.D., and ${ }^{3}$ James E. Lingeman, M.D.}

${ }^{1}$ Fellow in Endourology and SWL, Indiana University School of Medicine, Dept. of Urology ${ }^{2}$ Fellow in Endourology and SWL, Indiana University School of Medicine, Dept. of Urology ${ }^{3}$ Professor of Urology, Indiana University School of Medicine

Corresponding Author

James E. Lingeman, M.D., FACS

1801 North Senate Blvd., Suite 220

Indianapolis, IN 46202

Phone: 317/962-2485

FAX: $317 / 962-2893$

jlingeman@iuhealth.org

This is the author's manuscript of the article published in final edited form as:

York, N. E., Borofsky, M. S., \& Lingeman, J. E. (2015). Risks associated with drug treatments for kidney stones. Expert Opinion on Drug Safety, 14(12), 1865-1877. http://doi.org/10.1517/14740338.2015.1100604 


\section{Abstract}

Introduction: Renal stones are one of the most painful medical conditions patients experience. For many they are also a recurrent problem. Fortunately, there are a number of drug therapies available to treat symptoms as well as prevent future stone formation.

Areas covered: Herein, we review the most common drugs used in the treatment of renal stones, explaining the mechanism of action and potential side effects. Search of the Medline databases and relevant textbooks was conducted to obtain the relevant information. Further details were sourced from drug prescribing manuals. Recent studies of drug effectiveness are included as appropriate.

Expert opinion: Recent controversies include medical expulsive therapy trials and complex role of urinary citrate in stone disease. Future directions in research will involve new medical therapies for stone prevention, for example new drugs for hyperoxaluria.

\section{Keywords}

Adrenergic alpha-antagonists, analgesics, anti-inflammatory agents non-steroidal, bicarbonates, drug therapy, kidney calculi, renal colic, thiazides

\section{1 Introduction}

Renal stones are a common cause of morbidity around the world. The incidence of kidney stones is increasing globally ${ }^{1}$. These increases are seen across sex, race, and age and are multifactorial. In the USA, 20- to 74-year-old adults have at least a 5\%-8\% chance of being diagnosed with kidney stones during their lifetime ${ }^{2,3}$. There are a number of drugs used in stone treatment, 
prevention, and relief of associated symptoms. In this article we review the most common drugs prescribed for treatment and prevention of renal calculi as well as their potential adverse effects.

\subsection{Body}

The pharmacological management of renal calculi can be broadly divided into two categories: those that treat symptoms and those that treat progression of the stone disease as such. The choice of medications is dependent upon patient factors, stone analysis results and serum/urine biochemistry studies. Detailed patient work up is required before commencing any drug therapy.

\subsubsection{Drugs used to treat existing or prevent future stones}

The specific drug prescribed is dependent on the type of renal stone a particular patient forms as in many instances unique treatments are tailored to unique types of stones. This requires thorough patient evaluation and confirmatory laboratory studies. As an example, uric acid calculi can occasionally be dissolved with urinary alkalinisation by raising urinary $\mathrm{pH}$ to the 6.5 range $^{4}$. This treatment however might actually worsen stone formation in a patient who forms calcium phosphate stones. Furthermore, certain biochemical abnormalities (e.g. hypercalciuria) are known to predispose to stone formation ${ }^{5}$ and can be corrected with medications.

\subsubsection{Thiazides}

Thiazide diuretics are commonly used to reduce the risk of calcium stone recurrence. Common drugs and doses are listed in Table $1^{5}$. Thiazides exert their effect by reducing urinary calcium excretion, thereby reducing hypercalciuria. Thiazides can be effective in both normocalciuric and hypercalciuric patients. The beneficial effects have been confirmed in several studies ${ }^{6,7}$ over the last 55 years and are summarized in the recent AUA guideline on medical management of kidney stones $^{5}$. Thiazides directly stimulate calcium resorption in the distal nephron while reducing the 
extracellular fluid compartment. The hypocalciuric effect only takes 2-3 days to be established and is limited to thiazide types of diuretics only. It does not extend to other diuretic classes such as loop or potassium-sparing diuretics ${ }^{8}$. Significantly, thiazides can induce hypocitriuria due to hypokalemia and resultant intracellular acidosis. Potassium supplementation (in potassium chloride or potassium citrate form) will correct the hypocitriuria. Since citrate is a renal stone inhibitor, low citrate levels can contribute to stone formation ${ }^{9}$.

Table 1. Common diuretic doses for calcium stone prevention ${ }^{5}$

\begin{tabular}{|l|l|}
\hline Drug name & Dose \\
\hline Hydrochlorothiazide (HCTZ) & $25 \mathrm{mg}$ orally, twice daily \\
& OR \\
& $50 \mathrm{mg}$ once daily \\
\hline Chlorthalidone & $25 \mathrm{mg}$ orally, once daily \\
\hline Indapamide (non-thiazide diuretic) & $2.5 \mathrm{mg}$ orally, once daily \\
\hline Chlorothiazide ${ }^{10}$ & 0.5 -1g orally, once daily \\
& $*$ Liquid formulation* \\
\hline Amiloride / HCTZ ${ }^{11}$ & $5 \mathrm{mg} / 50 \mathrm{mg}$ tablet, once daily \\
\hline Triamterene / HCTZ & \\
\hline
\end{tabular}

While generally well tolerated at low doses, the potential for side effects with thiazides is present. In some studies the side effects are significant enough to stop treatment in 1:6 patients. In the majority of cases; however, they do improve with time ${ }^{13,8}$. The most common side effects are dizziness (due to postural hypotension), weakness and fatigue. Other potential side effects include thirst, polyuria, muscle cramps, reversible erectile dysfunction, nausea, vomiting, gastric 
irritation, diarrhea or constipation, rashes, skin reactions, purpura and blood dyscrasias including thrombocytopenia. Uncommonly, precipitation of gout or diabetes can occur; very rarely pancreatitis and hepatic encephalopathy have been reported ${ }^{14}$. Gout and diabetes precipitation is likely due to disturbances of serum uric acid and glucose levels that have been described with thiazide administration ${ }^{14}$. It is essential to obtain serum potassium measurement when starting thiazide treatment as hypokalemia can occur (due to indirect stimulation of potassium excretion ${ }^{15}$ ). This is particularly true in the context of dehydration e.g. vomiting and diarrhea. Serial serum potassium levels should be checked at regular intervals. It is recommended that concomitant potassium supplementation be administered whenever a thiazide is commenced. Thiazide use requires caution in renal or liver failure and elderly patients. Mild hypercalcemia is not uncommon. Occasionally administration of a thiazide can unmask primary hyperparathyroidism ${ }^{8}$. Finally, there are several important drug interactions detailed in table 2.

Table 2. Diuretics in renal stone disease - important drug interactions ${ }^{16}$

\begin{tabular}{|l|l|l|l|}
\hline Drug & Hydrochlorothiazide & Chlorthalidone & Indapamide \\
\hline Cardiovascular & Alcohol, barbiturates & Alcohol, barbiturates & \\
& or narcotics & or narcotics & \\
exacerbate orthostatic & exacerbate orthostatic & \\
& hypotension & hypotension & \\
\hline Altered drug effects & $\begin{array}{l}\text { Diabetic drugs - may } \\
\text { require dose }\end{array}$ & $\begin{array}{l}\text { Potentiate action of } \\
\text { other }\end{array}$ & $\begin{array}{l}\text { May potentiate other } \\
\text { antihypertensives. }\end{array}$ \\
& adjustment. & antihypertensives. & Diabetic drugs - may \\
& NSAIDS - reduce & Diabetic drugs - may & require dose \\
\hline
\end{tabular}




\begin{tabular}{|c|c|c|c|}
\hline & $\begin{array}{l}\text { diuretic/ natriuretic } \\
\text { function }\end{array}$ & $\begin{array}{l}\text { require dose } \\
\text { adjustment }\end{array}$ & adjustment \\
\hline $\begin{array}{l}\text { Impaired drug } \\
\text { absorption }\end{array}$ & $\begin{array}{l}\text { Anionic exchange } \\
\text { resins } \\
\text { (e.g. cholestyramine, } \\
\text { colestipol) reduce } \\
\text { thiazide absorption }\end{array}$ & & \\
\hline Metabolic effects & $\begin{array}{l}\text { Corticosteroids and } \\
\text { ACTH hormone may } \\
\text { intensify electrolyte } \\
\text { depletion }\end{array}$ & $\begin{array}{l}\text { Corticosteroids and } \\
\text { ACTH hormone may } \\
\text { intensify electrolyte } \\
\text { depletion. } \\
\text { Digitalis may worsen } \\
\text { hypokalemia effects, } \\
\text { derange electrolytes }\end{array}$ & $\begin{array}{l}\text { Corticosteroids, and } \\
\text { ACTH hormone may } \\
\text { intensify electrolyte } \\
\text { depletion. } \\
\text { Digitalis may worsen } \\
\text { hypokalemia effects, } \\
\text { derange electrolytes }\end{array}$ \\
\hline Toxicity & $\begin{array}{l}\text { Increased lithium } \\
\text { toxicity risk }\end{array}$ & $\begin{array}{l}\text { Increased lithium } \\
\text { toxicity risk }\end{array}$ & $\begin{array}{l}\text { Increased lithium } \\
\text { toxicity risk }\end{array}$ \\
\hline Contraindications & $\begin{array}{l}\text { Sulfonamide-derived } \\
\text { drug hypersensitivity } \\
\text { (relative) }\end{array}$ & $\begin{array}{l}\text { Sulfonamide-derived } \\
\text { drug hypersensitivity } \\
\text { (relative) }\end{array}$ & $\begin{array}{l}\text { Sulfonamide-derived } \\
\text { drug hypersensitivity } \\
\text { (relative) }\end{array}$ \\
\hline
\end{tabular}

Indapamide is an indoline-class diuretic, similar to thiazides in its effect on urinary calcium excretion ${ }^{17}$. It is utilized in calcium stone prevention with fewer side effects than thiazide 
diuretics ${ }^{18}$. Cases of severe hyponatremia have been reported. Indapamide should not be used in severe renal or hepatic disease ${ }^{19}$.

Amiloride is a diuretic commonly administered together with thiazide. Amiloride does not affect potassium excretion, reducing the risk of hypokalemia. In fact, in certain high risk patients, e.g. renal failure it can cause hyperkalemia, necessitating a boxed FDA warning. Caution will be required if other potassium containing medications are used or in patients with renal impairment ${ }^{20}$. Amiloride can cause hypocalciuria, thereby potentiating this effect of thiazide diuretics when given in combination ${ }^{21}$.

\subsubsection{Urinary alkalinizers}

Urinary alkalinizers such as potassium citrate can be used in patients with hypocitriuria. Increased urinary citrate increases the $\mathrm{pH}$ of urine and can act as an inhibitor of calcium oxalate and calcium phosphate stone formation ${ }^{22,23}$. Urinary inhibitors, such as citrate, prevent crystal growth and aggregation by coating the surface of the growing calcium crystals without changing the concentration of calcium oxalate or phosphate. In the case of citrate, stone inhibition is achieved by it forming a complex with urine calcium, thereby directly decreasing the saturation of calcium oxalate and calcium phosphate ${ }^{24}$. Citrate is also an inhibitor of crystallization ${ }^{25}$. Important causes of low urinary citrate excretion associated with renal stone disease include use of thiazides, renal tubular acidosis, urinary tract infection, hypokalemia associated with potassium depletion, magnesium depletion, bowel disease and idiopathic causes. Interestingly, irrespective of dietary intake, most of the circulating citrate is derived endogenously from oxidative metabolism ${ }^{26}$. Randomized trials have confirmed that potassium citrate administration reduces the risk of recurrent calcium stones ${ }^{5}$. Furthermore, alkalinizers can be utilized in thiazide-induced hypocitriuria and in uric acid calculi dissolution and prevention therapy. They 
are also a useful adjunct in patients with renal tubular acidosis type 1 and cystinuria. One must be cautious not to over alkalinize the urine as doing so can lead to a net increase in the risk of calcium phosphate stone formation whose growth is favored by an alkaline urinary $\mathrm{pH}^{5}$.

There is a range of doses and formulations available, from tablets (UROCIT®-K Mission Pharmacal Company) and liquids to effervescent drinks ${ }^{27}$. Several formulations are detailed in Table 3. A more extensive list is available in the Appendix.

Table 3. Common urinary alkalinizers

\begin{tabular}{|l|l|l|l|l|}
\hline Drug & UroCit-K $\mathrm{K}^{28}$ & Polycitra-K $\mathrm{K}^{29}$ & Oracit $^{30}$ & Bicitra $^{31}$ \\
\hline Active & Potassium citrate & Potassium citrate & Sodium citrate & Sodium citrate \\
\hline Formulation & Extended release & Crystals or liquid & Liquid & Liquid \\
\hline tablets & $\begin{array}{l}1 / 2 \mathrm{mEq} / \mathrm{kg} / \text { day } \\
\text { in divided doses }\end{array}$ & $\begin{array}{l}30 \text { to } 60 \\
\mathrm{mEq} / \text { day }\end{array}$ & $\begin{array}{l}10 \text { to } 30 \mathrm{~mL} \\
\text { diluted, after } \\
\text { mose }\end{array}$ & $\begin{array}{l}10 \text { to } 30 \mathrm{~mL} \\
\text { diluted, after } \\
\text { meals }\end{array}$ \\
\hline
\end{tabular}

The two primary alkalinizer categories are potassium citrate compounds and sodium citrate compounds. Sodium citrate is not recommended as increased sodium load will increase urinary calcium levels $^{32}$. The most common side effect is gastrointestinal upset, improved by taking the drug with water and soon after a meal ${ }^{33}$. The most dangerous effect of potassium containing supplements is hyperkalemia, particularly dangerous in patients with renal failure ${ }^{23}$. This can be life-threatening, especially in combination with potassium-sparing diuretic therapy. Careful 
serum electrolyte monitoring is required. In such cases, sodium containing supplements may be preferred as they avoid the hyperkalemia risk. However, these are suboptimal for stone formers as the increased sodium load can increase urinary calcium excretion, with increased risk of calcium stones ${ }^{32}$, thereby offsetting the beneficial effects of urinary alkalinization. High doses of sodium containing supplements can cause fluid overload in patients with pre-existing renal dysfunction or cardiac failure. Other precautions for urinary alkalinizers include presence of struvite stones and upper GI tract disease such as ulcers, gastritis and delayed gastric emptying ${ }^{34}$. A starting dose of UROCIT®-K Mission Pharmacal Company is $1 / 2 \mathrm{mEq} / \mathrm{kg} /$ day in divided doses. Typically, the dose of alkalinizer is titrated until desired urinary pH (e.g. 6-6.5) is achieved. Raising urinary $\mathrm{pH}$ to $>7$ can increase risk of calcium phosphate stones and should be avoided ${ }^{5}$. This is due to an increase in the saturation of calcium phosphate at high $\mathrm{pH}$. Increased urine $\mathrm{pH}$ shifts the equilibrium between $\mathrm{HPO}_{4}{ }^{2-}$ and $\mathrm{H}_{2} \mathrm{PO}_{4}{ }^{-}$in favor of the former, thereby tending to precipitate out the less soluble brushite $\left(\mathrm{CaHPO}_{4} \cdot 2 \mathrm{H}_{2} 0\right)$.

Calcium citrate can be used to bind oxalate in the gut in enteric hyperoxaluria ${ }^{35}$. It will also increase urinary citrate excretion thereby offsetting increased urinary calcium excretion ${ }^{36}$. A recommended dose is $200-400 \mathrm{mg}$ and must be taken with meals to maximize oxalate binding effect and minimize calcium absorption ${ }^{37}$.

\subsubsection{Xanthine oxidase inhibitors}

These drugs are commonly used in patients with hyperuricosuria and either uric acid or calcium stones. Uric acid stones account for approximately 9\% of renal calculi in the USA ${ }^{38}$. Furthermore, monosodium urate or uric acid crystals can act as seed crystals for calcium oxalate or adsorb normally occurring inhibitors of calcium oxalate crystallization ${ }^{39}$. It is important to note that the majority of patients with uric acid calculi have low urinary $\mathrm{pH}$ and normal urinary 
uric acid levels ${ }^{40,41}$. Allopurinol is a xanthine oxidase inhibitor that reduces both serum and urinary uric acid levels. It was first noted as part of the drug discovery program at Burroughs Wellcome that started in 1940s and culminated in a 1988 Nobel Prize in Physiology and Medicine. Although generally well tolerated, the most common adverse effects of allopurinol are gastrointestinal distress, hypersensitivity reactions, hepatotoxicity and skin rash ${ }^{42,43}$. Minor hypersensitivity reactions to allopurinol, including pruritus and dermatitis, occur in approximately $2 \%$ of patients ${ }^{44}$. More serious adverse events associated with allopurinol include fever, toxic epidermal necrolysis, alopecia, bone marrow suppression, hepatitis, and vasculitis ${ }^{43}$. Severe allopurinol-induced toxic effects are rare but can be life-threatening. A dose dependent allopurinol hypersensitivity syndrome is associated with a mortality rate of approximately $20 \%{ }^{45}$. Several drug interactions can also occur. Increased toxicity with thiazide diuretics has been noted (patients who are already taking thiazides for hypercalciuria are at a particular risk) and renal and hepatic function monitoring is required ${ }^{46}$.

Febuxostat is a new type of xanthine oxidase inhibitor. It is preferred in renal impairment as it is hepatically cleared ${ }^{47}$. A recent 2013 trial showed that febuxostat significantly lowered 24-hour urinary acid excretion in patients with calcium stones, compared to allopurinol. There was no change in stone size or number, although the study was only six months in duration ${ }^{48}$. Adverse reactions occurring in at least $1 \%$ of Febuxostat-treated patients, and at least $0.5 \%$ greater than placebo, are: liver function abnormalities, nausea, arthralgia, and rash ${ }^{49}$. Trials of febuxostat for uric acid and calcium calculi prevention are still awaited.

\subsubsection{Treatments for cystinuria}

Cystinuria is an inherited autosomal recessive condition, due to a defect in intestinal and renal tubular transport of dibasic amino acids, including cystine ${ }^{50}$. As a result of high urinary cystine 
levels and poor solubility of cystine these patients form multiple stones, often from an early age. Initial therapy involves hydration to reduce cystine concentration and reduced oral intake of sodium and protein. Urinary alkalinization is the next step, aiming for $\mathrm{pH}>7^{51}$ since higher urinary $\mathrm{pH}$ increases solubility of cystine ${ }^{52}$. Potassium citrate, as discussed above, is frequently utilized. If these simple measures are inadequate, additional medications are used.

\subsection{Tiopronin (Thiola ${ }^{\circledR}$ Mission Pharmacal Company)}

Tiopronin is the active reducing agent that undergoes thiol-disulfide exchange with cystine to form a mixed disulfide of Thiola-cysteine ${ }^{53}$. This mixed disulfide is far more soluble than cystine, thereby reducing pure cystine excretion and stone formation. The drug is only available in a 100mg tablet form. Exact dose is dependent on the desired reduction in the urinary cystine excretion. Urinary cystine concentrations are monitored with 24-hour urine testing, so that dose adjustments can be made. Typically, the urinary cystine concentration target is $<300 \mathrm{mg} / \mathrm{L}$ (cystine solubility limit) to be maximally effective ${ }^{54}$. An average dose in the study of cystinuria patients was approximately 1100mg/day. Tiopronin has fewer side effects than d-penicillamine, a drug also used in cystinuria treatment. Nevertheless, both drugs have significant side effects with $30 \%$ of patients needing to stop treatment in one study ${ }^{55}$. Tiopronin side effects include drug fever, rash and pruritus (1 in 6 patients), as well as SLE-type reaction and skin changes with longer term use. Gastrointestinal side-effects occur in 1 in 6 patients, including nausea, vomiting, diarrhea and abdominal pain. Significantly, there is a 1 in 25 risk of hematological abnormalities including bleeding, anemia, leukopenia, thrombocytopenia and eosinophilia ${ }^{53}$. Other less common effects include hypersensitivity reactions, renal complications including proteinuria and nephrotic syndrome (1 in 20 patients) and pulmonary manifestations including bronchiolitis, hemoptysis and dyspnea in 1 in 50 patients. Unfortunately, severe reactions are more likely to 
occur in patients who already developed adverse effects with another cystinuria drug, dpenicillamine. Given these significant side effects, close monitoring including frequent hematological, renal and liver function testing is essential.

\subsection{D-penicillamine}

D-penicillamine acts similar to tiopronin by forming penicillamine-cysteine disulfide that has higher solubility than cystine. Since the side effects are more significant, it is usually reserved as a second-line option. Significant hematological side effects including leukopenia, thrombocytopenia, pancytopenia, aplastic anemia and agranulocytosis have been reported, even leading to fatalities ${ }^{56}$. Proteinuria and hematuria can also develop, progressing to nephrotic syndrome. Hemoptysis and pulmonary infiltrates can also occur. Skin rashes and pemphigus occur in a small number of patients as does myasthenic syndrome. Myasthenic syndrome is characterized by progressive, and typically symmetric, muscle weakness. With D-penicillamine, symptoms usually start 4 to 9 months after initiation of treatment ${ }^{57}$. The symptoms are generally mild and may be limited to extra ocular muscles. Close monitoring of hematological, renal and hepatic parameters is mandatory, initially with twice-weekly tests and clinical examination. Typical dose starts with $250 \mathrm{mg}$ /day and is increased to $500 \mathrm{mg}$ qid as required to reduce urinary cystine concentration.

\subsection{Captopril}

Captopril is an ACE inhibitor that contains thiol compounds. There are literature reports of its use in cystinuria ${ }^{58,59}$. However other studies have failed to confirm effectiveness ${ }^{60,61}$. As a result it is not routinely used in the treatment of cystinuria patients unless there is the presence of concomitant hypertension. 


\subsubsection{Acetohydroxamic acid (AHA)}

Struvite stones form as a result of urinary tract infection with urease-splitting organisms, including Proteus, Pseudomonas and Klebseilla (Table 4). The hydrolysis of urea by bacterial urease enzyme increases urinary $\mathrm{pH}$ and ammonia levels, with consequent stone formation ${ }^{62}$.

Table 4. Urease-producing microorganisms ${ }^{63}$

\begin{tabular}{|c|c|c|}
\hline Organism & $\begin{array}{l}\text { Usually produces urease } \\
\text { (>90\% of isolates) }\end{array}$ & $\begin{array}{l}\text { Occasionally produces urease } \\
\text { (5-30\% of isolates) }\end{array}$ \\
\hline $\begin{array}{l}\text { Gram positive } \\
\text { bacteria }\end{array}$ & Staphylococcus aureus & Staphylococcus epidermidis \\
\hline $\begin{array}{l}\text { Gram negative } \\
\text { bacteria }\end{array}$ & $\begin{array}{l}\text { Proteus mirabilis } \\
\text { Proteus subspecies (vulgaris, } \\
\text { rettgeri, morgani) } \\
\text { Providencia stuartii } \\
\text { Providencia rettgeri } \\
\text { Enterobacter gergoviae }\end{array}$ & $\begin{array}{l}\text { Klebsiella pneumoniae } \\
\text { Klebsiella oxytoca } \\
\text { Serratia marcescens } \\
\text { Pseudomonas aeruginosa }\end{array}$ \\
\hline Yeasts & $\begin{array}{l}\text { Cryptococcus } \\
\text { Rhodotorula } \\
\text { Sporobolomyces } \\
\text { Candida humicola } \\
\text { Trichosporon cutaneum }\end{array}$ & \\
\hline
\end{tabular}


Classically, these bacteria form staghorn calculi, often requiring invasive surgical treatment. Acetohydroxamic acid binds urease, inhibiting its action and reducing the likelihood of struvite stone formation ${ }^{64}$. It does not acidify urine or have a direct antibacterial effect. It is used in patients with urease-splitting UTI at a dose of $1 \mathrm{~g}$ /day in divided doses. AHA is utilized after surgical treatment options have been exhausted, given its significant side-effects 5 in up to $30 \%$ of patients ${ }^{65}$. Common reactions include tremors, headache (mild and transient), gastrointestinal symptoms (primarily mild) and alopecia. Regular hematologic testing is required as hemolytic anemia occurs in 3-15\% of patients necessitating cessation of the medication. Mild hemolysis occurs in most patients as evidenced by elevated reticulocyte counts. If the reticulocyte count exceeds 6\%, a reduction in dosage should be considered ${ }^{66}$. Superficial phlebitis and embolic phenomena were reported in a small number of patients, resolving with discontinuation of AHA. Finally, depression, anxiety and nervousness were significant enough to stop treatment in $6 \%$ of patients ${ }^{65}$. AHA should not be administered to patients with renal impairment as it can lead to drug accumulation with resultant toxicity. Furthermore, clinical experience with this drug is limited with long-term effects unknown. Due to its toxicity and expense, AHA is indicated only in patients with recurring struvite stone formation and recalcitrant urealysis who are not suitable for surgical stone treatment.

\subsubsection{Drugs used in managing stone symptoms}

Acute renal colic is considered to be one of the most excruciatingly painful medical conditions. A range of analgesia options is available to control acute symptoms. As always, full medical history, examination and appropriate tests are conducted before drugs are prescribed. In particular, renal function can be affected by renal calculi causing obstruction. Significant renal impairment will preclude the use of several analgesics. 


\subsubsection{Acetaminophen}

Acetaminophen is one of the most commonly prescribed analgesics around the world. It has an excellent safety profile. Despite its popularity and use for over 100 years, the mechanism of action is still not fully elucidated. It is thought to have a weak cyclooxygenase inhibitor action ${ }^{67}$. Acetaminophen has potent anti-pyretic and analgesic actions, despite very weak antiinflammatory activity. It is used as part of the acute management of renal colic. In randomized trials intravenous acetaminophen was as effective as intravenous morphine in relieving acute renal colic pain ${ }^{68,69}$. As for any drug, there is a small risk of hypersensitivity reaction. High doses $>4000 \mathrm{mg} / 24$ hours or together with high alcohol intake can cause severe liver damage ${ }^{70}$. Caution is required in patients with liver or kidney impairment. Thrombocytopenia and hepatic dysfunction (at recommended doses) have been reported very rarely $\left(<1 / 10,000\right.$ patients) ${ }^{71}$. Immediate medical attention is warranted in the event of an overdose due to risk of permanent liver injury, and may require administration of N-Acetyl-Cysteine ${ }^{72}$.

\subsubsection{Cyclooxygenase inhibitors}

Cyclooxygenase (COX) enzyme produces prostaglandins. These are mediators of multitude of bodily functions, from physiological, such as gastric protection, platelet and renal function, to pathological, such as fever, pain and inflammation ${ }^{73}$. In particular, PGE2 and prostacyclin are the main inflammatory mediators. Aspirin, diclofenac, ketorolac and similar non-steroidal antiinflammatory drugs (NSAIDs) inhibit cyclooxygenase prostaglandin synthesis and therefore have anti-inflammatory, antipyretic and analgesic effects. These are some of the most commonly used drugs for management of renal colic. In a 2004 systematic review of 20 trials, 1613 patients given NSAIDs for renal colic achieved greater reductions in pain scores, were less likely to

require rescue analgesia or develop vomiting than patients given opioids ${ }^{74}$. In a Cochrane review 
of 5734 patients from 2015, NSAIDs were again shown to be effective in acute renal colic ${ }^{75}$. However, these powerful drugs are not without problems. Due to disruption of protective functions of prostaglandins, NSAIDs can cause a range of side effects. An important adverse effect of NSAIDs is renal impairment, particularly relevant to patients with renal stones who may already have a degree of renal dysfunction, either acutely (due to urinary tract obstruction) or chronically. NSAIDS inhibit prostaglandin synthesis therefore reducing renal cortical blood flow $^{76}$. Furthermore, NSAIDS can cause interstitial nephritis with nephritic syndrome and (rarely) irreversible renal papillary necrosis ${ }^{77}$. Hence, renal function monitoring is essential in any patients taking these drugs. NSAIDS are contraindicated in patients with significantly reduced renal function.

NSAIDs have increased risk of gastrointestinal inflammation, bleeding, ulceration and even perforation ${ }^{78}$. This warrants careful review, if not outright contra-indication of NSAIDs in patients with pre-existing gastric ulcers. Risk factors for NSAID-related GI complications include a previous GI event (especially if complicated), age, concomitant use of anticoagulants, corticosteroids, other NSAIDs including low-dose aspirin, high-dose NSAID therapy, and chronic debilitating disorders, especially cardiovascular disease ${ }^{79}$. In selected patients, after assessing their GI ulceration risk factors, proton pump inhibitors (e.g. omeprazole) can be used to reduce risk of gastric and duodenal ulcers and their complications ${ }^{79}$. Finally, any high-risk patients starting long-term NSAID therapy should be tested for and treated for $\mathrm{H}$. Pylori infection first ${ }^{80}$. NSAIDS can also increase cardiovascular thrombotic risks including MI and stroke, necessitating a boxed FDA warning in the USA. Hence, patient's cardiovascular risk profile needs to be assessed prior to starting NSAID treatment. Other side effects of COX inhibitors include fluid retention, hypertension, anaphylactoid reaction, skin reactions 
(exfoliative dermatitis, Stevens-Johnson syndrome), worsening of asthma control, anemia, prolonged bleeding time and liver dysfunction. Prolonged bleeding time and coagulopathic effects are significant in renal stone patients who may require surgery ${ }^{78}$. While minimally invasive ureteroscopy and laser lithotripsy can safely be performed with anticoagulation ${ }^{81}$, procedures such as ESWL and PCNL will require cessation of NSAIDs (with or without bridging therapy, as dictated by the thrombotic risk profile).

\subsubsection{Ketorolac}

Ketorolac tromethamine is one of the most commonly used NSAID drugs for the treatment of renal colic. In addition to inhibiting prostaglandin synthesis, it may act centrally to diminish perception of pain and reduce ureteric musculature activity ${ }^{82}$. It is typically given in IV or IM form. Tablets (only as continuation of IV form) are also available. Ketorolac has been shown to be more effective than meperidine (narcotic analgesic) in renal colic ${ }^{83}$. Ketorolac carries a boxed FDA warning with total combined duration of oral and injectable use not to exceed 5 days ${ }^{84}$. Ketorolac side effects are representative of NSAID class in general, including GI bleeding and ulceration, increased risk of cardiovascular thrombotic events, MI and stroke. It should not be used prior to any major surgery, in patients at risk of renal impairment, or in patients $>70$ years of age. Prolonged bleeding time and coagulopathic effects are noted as with the rest of the NSAID medications. Common adverse reactions include nausea, dyspepsia, abdominal pain, dizziness and drowsiness.

\subsubsection{COX-2 inhibitors}

A newer class of drugs, COX-2 inhibitors, acts by suppressing inflammatory mediators produced specifically by COX-2 enzyme. COX-1 enzyme has protective physiological functions, such as 
anti-thrombogenic and cytoprotective effects. COX-2 enzyme is primarily expressed in response to inflammation or other pathological event ${ }^{73}$. Hence, specific COX-2 inhibitors such as celecoxib and parecoxib are thought to possess less (although not negligible) gastrointestinal toxicity. Unfortunately, as demonstrated in VIGOR study (and ensuing controversy) this comes at a price of increased myocardial infarction and stroke rates ${ }^{85}$. Following the fall-out from the VIGOR trial, rofecoxib has been withdrawn from the market. Other COX-2 inhibitors carry boxed FDA warning of increased cardiovascular and stroke events ${ }^{86}$. Patients with pre-existing cardiovascular or GI ulcer disease (or risk factors) should avoid COX-2 inhibitors. Other side effects of COX-2 inhibitors include onset of or worsening hypertension and fluid retention. Hepatic reactions can occur and liver function tests (LFTs) need to be monitored ${ }^{86}$. Renal impairment risk is noted, particularly with long-term use. This has implications for renal calculi patients who frequently have either acute or chronic renal impairment. As with other NSAIDs, asthmatic patients may develop worsening symptoms. Rarely, serious skin reactions e.g. exfoliative dermatitis and Stevens-Johnson syndrome have been reported. While COX-2 inhibitors have been previously studied in the management of renal colic ${ }^{87}$, due to increased cardiovascular risks their current use is limited, especially in the setting of renal colic.

\subsubsection{Opioid analgesics}

Opiods are a large class of analgesics, including diverse drugs such as morphine, hydrocodone, oxycodone, fentanyl, codeine and methadone. Opiods are available in oral, intramuscular and intravenous formulations. The earliest opioids were derived from the seeds of poppy plants. Opioid drugs are typically reserved for more severe pain conditions, when alternative medications are ineffective. Opioids mimic the actions of endogenous opioid peptides by interacting with mu, delta or kappa opioid receptors in the central nervous system. They also 
decrease intracellular cAMP which modulates the release of nociceptive neurotransmitters (e.g. substance $\mathrm{P})^{88}$. Opioids have been shown in systematic review to be effective in management of renal colic (albeit less effective than NSAIDS) ${ }^{74}$. Unfortunately, opioids can cause a number of unpleasant side effects. Most common effects include gastrointestinal (nausea, vomiting, constipation) and central nervous system (drowsiness, hypotension and respiratory depression) ${ }^{89}$. In particular, patients with respiratory or renal impairment (more frequent amongst patients with renal colic) are at increased risk of opioid accumulation and resultant respiratory depression. In certain patients at risk (e.g. elderly and cachectic, other CNS depressants, renal impairment) respiratory depression can be life-threatening. Other opioid side effects include headache, peripheral edema, rash, insomnia and depression ${ }^{90}$. Any patient on opioid medications can develop opioid tolerance and potential for abuse/addiction. This is a significant issue, requiring boxed FDA warning in USA. Tolerance develops with the repeated use of opioids requiring increasing doses to maintain analgesic effects ${ }^{91}$. Rotation of various opioid drugs can be useful in managing tolerance. Meperidine in particular has high risk of developing tolerance ${ }^{92,93}$. It also carries a risk of serotonin syndrome when combined with certain medications, such as antidepressants $^{94}$. Given these concerns, meperidine use in the US has declined significantly, although it remains in use worldwide.

\subsubsection{Tramadol}

Tramadol is an atypical opioid analgesic. Its mechanism of action is two-fold, mediated by opioid (mu) and non-opioid (inhibition of monoamine uptake) pathways ${ }^{95}$. Many of the side effects are similar to the opioid drugs, although potential for tolerance and addiction is lower. There is some evidence of its use for renal colic ${ }^{96}$ but further studies are needed. Common adverse effects include dizziness, nausea and vomiting, constipation, headache, drowsiness, 
sweating, dry mouth, dyspepsia, diarrhea and pruritus ${ }^{97}$. Tramadol is known to lower seizure threshold in patients with epilepsy or head injury. Caution needs to be exercised in patients with emotional disturbances, depression and in elderly. Finally, there is risk of serotonin syndrome if used concurrently with SSRIs, tricyclic antidepressants or MAOIs ${ }^{98}$. Serotonin syndrome is a rare and potentially life-threatening toxic state due to excessive serotonergic activity. It classically presents with altered mental status, abnormal neuromuscular tone and autonomic hyperactivity and is typically treated with cessation of offending drug and supportive care ${ }^{99}$.

\subsubsection{Phenazopyridine hydrochloride}

Phenazopyridine hydrochloride (Pyridium ${ }^{\circledR}$ Gemini Laboratories, LLC) is a urinary tract analgesic that exerts a topical analgesic effect on urinary tract mucosa. It is particularly useful for treatment of dysuria, frequency and urgency associated with stone passage or stone surgery. It is also helpful for management of stent symptoms ${ }^{100}$. A typical dose is $200 \mathrm{mg}$ tablets three times daily. Common adverse effects include headache, rash, pruritus and GI disturbance. It is contraindicated in renal insufficiency ${ }^{101}$. The drug causes reddish-orange discoloration of urine and may stain fabric and contact lenses. It should not be used for more than a few days as it can mask important symptoms such as infection.

\subsubsection{Alpha-blockers}

Alpha-1-adrenergic receptor antagonists are used in the medical management of ureteric stones as part of MET (medical expulsion therapy). MET uses drugs to relieve symptoms in uncomplicated renal colic thereby reducing the need for invasive procedures as some stones will pass spontaneously. The alpha- 1 adrenergic receptors are predominantly located in the distal ureter $^{102}$. Administration of alpha-1-adrenergic blockers can improve expulsion rates of distal 
ureteric stones as it allows relaxation of the ureteric muscle ${ }^{103}$, although this is an off-label use. Alpha-1-adrenergic blockers are also used as an aide in shock wave lithotripsy to improve stonefree rates. Alpha-blockers have also been useful in reducing stent-associated symptoms and pain $^{104}$. Common alpha-1 blockers include terazosin and doxazosin. Usual dosing is outlined in Table 5. Significant side effects include postural hypotension and syncope (vasodilatation due to the adrenergic blockade effects). Gradual dose titration and administration at night are recommended to reduce these unwelcome effects ${ }^{105}$. Other side effects are asthenia, headache, nasal congestion, nausea, peripheral edema and priapism.

\section{Table 5 - Common alpha-blockers}

\begin{tabular}{|l|l|l|l|l|}
\hline Drug & Terazosin & Doxazosin & Tamsulosin & Alfuzosin SR \\
\hline Mechanism of & $\alpha_{1}$ blocker & $\alpha_{1}$ blocker & $\begin{array}{l}\alpha_{1 \mathrm{a}} / \alpha_{1 \mathrm{~d}} \text { receptor } \\
\text { blocker }\end{array}$ & $\begin{array}{l}\alpha_{1} \text { blocker } \\
\text { slow release }\end{array}$ \\
\hline Typical dose & $5 \mathrm{mg}$ daily & $2-4 \mathrm{mg}$ daily & $0.2-0.4 \mathrm{mg}$ daily & $10 \mathrm{mg}$ \\
\hline
\end{tabular}

Tamsulosin is an alpha-adrenergic antagonist with equal affinity for $\alpha_{1 \mathrm{a}}$ and $\alpha_{1 \mathrm{~d}}$ receptors ${ }^{106}$. Since the $\alpha_{1 d}$ receptor is the predominant subtype in the ureter ${ }^{107}$, tamsulosin blockade can improve ureteric relaxation. Tamsulosin has been shown to improve stone passage rates by up to a third in several studies, including by De Sio et al in $2006^{108}$. It also reduced both the requirement for analgesia and mean stone passage time. However, in 2015 a large randomized trial of 1167 patients (SUSPEND trial) assessing the efficacy of alpha blockers (and calcium channel blockers) vs. placebo failed to demonstrate a significant benefit in stone passage ${ }^{109}$. Tamsulosin has similar side-effect profile to other alpha-1 blockers but without the need for dose 
titration, allowing greater convenience for the patients at therapy initiation. Tamsulosin has a slightly higher incidence of ejaculatory dysfunction, due to its affinity for dopaminergic and other central nervous system receptors ${ }^{110}$.

Alfuzosin SR is another $\alpha_{1}$ selective blocker, with reduced risk of ejaculatory dysfunction ${ }^{111}$. It has also been shown to reduce stent symptoms in a randomized trial ${ }^{112}$.

\subsubsection{Corticosteroids}

Corticosteroid drugs, such as prednisolone and deflazacort have potent anti-inflammatory effects. It is thought that these anti-inflammatory effects may improve stone passage by relieving ureteric edema resulting from stone impaction ${ }^{113}$. Several trials had showed faster stone passage with the addition of corticosteroid ${ }^{114,115}$. However, routine use of corticosteroids is limited by the significant adverse effects. The potent anti-inflammatory actions suppress immune response to intercurrent infections. Corticosteroids can cause salt/water retention, muscle weakness, Cushinoid state, impaired glucose tolerance, impaired wound healing and osteoporosis. Hence these medications are rarely used in managing renal stone disease.

\subsubsection{Rowatinex}

Rowatinex is an essential oil preparation of terpenic type. Terpenes are known to have diuretic and antibacterial effects as well as spasmolytic and hyperemic effects. Rowatinex was first shown to be effective in a small randomized trial in $1987^{116}$. In a randomized study of 222 patients in 2011 it was shown to be more effective than placebo in stone clearance after ESWL $^{117}$. Treatment with the terpene combination is well tolerated. However, in another randomized trial of 100 patients published in 2009, while Rowatinex improved initial stone 
passage there was no clinical difference at the trial end ${ }^{118}$. And in a 90 patients trial by Aldemir et al. in 2011 Rowatinex was inferior to tamsulosin in stone expulsion rates ${ }^{119}$.

\subsubsection{Calcium-channel blockers}

Nifedipine, an antihypertensive drug, has been the most studied of calcium-channel blockers. Similar to alpha-1 blockers it is used as part of medical expulsive therapy for selected ureteric stones, although it may be less effective ${ }^{114}$. In the recent SUSPEND trial it was to be no more effective than placebo ${ }^{109}$. Nifedipine reduces contractility of the distal ureter similarly to alphaadrenergic blockers allowing improved stone passage ${ }^{120}$. It is used off-label for medical expulsion therapy. Predictably, Nifedipine can cause dizziness and hypotension and can therefore precipitate or worsen underlying ischemic heart disease. Other side effects include peripheral edema, liver function test derangement and cholestasis or even allergic hepatitis ${ }^{121}$. Patients can experience flushing, headache, weakness, nausea, muscle cramps and tremor.

\subsection{Conclusion}

There are many different pharmacologic treatments available for the treatment of urinary tract stones. However, each has unique benefits and harms and tailored treatment strategies are necessary in order to appropriately utilize the available options. As we learn more about the

mechanisms and etiology of stone formation itself we are hopeful that novel agents continue to be developed to optimally treat patients afflicted with this disease

\subsection{Expert opinion}

This paper provides an up-to-date summary of the literature on medical management of renal stone disease. Key findings include strong evidence for thiazide and potassium citrate use in calcium stones and widespread and effective use of NSAID medications for management of 
renal colic pain. The subject of MET (medical expulsive therapy) with alpha ${ }_{1}$ blockers or calcium-channel blockers remains controversial owing to a recent randomized controlled trial of over 1100 patients with no evidence of improved stone passage in the treatment vs. placebo groups ${ }^{109}$. Despite this finding, some are critical of the fact that the study was not specifically powered to detect a difference in distal ureteral stones where the effect of MET is felt to be the strongest. Furthermore, these findings go against the results of previously published metaanalyses ${ }^{113}$ and are sure to generate discussion, in particular relating to stone management guidelines. Another area requiring further study is the complex metabolism of citrate, acting as a stone inhibitor while simultaneously raising urinary $\mathrm{pH}$ with increased risk of calcium phosphate stone formation. Further studies are required to evaluate this process in more detail. With regard to stone prevention, the only recent new drug used for stone prevention is febuxostat. A trial in $2013^{48}$ has confirmed significantly lowered 24-hour uric acid excretion. However, as yet we have no data on calcium or uric acid stone prevention with this drug. The majority of trials on stone prevention are more than 25 years old. In the meantime our understanding of stone disease has evolved significantly and there may well be multiple new avenues for intervention. For example, a pharmaceutical company is currently trialing a new oxalate-reducing drug ${ }^{122}$ that may be of benefit in patients with hyperoxaluria. Perhaps, one day in the future we will have a full armamentarium of effective medical options to prevent various stone types so that surgical treatment is only of historical interest. 


\section{Article highlights}

- Renal stones are common and cause significant morbidity

- Thiazide-type diuretics reduce urinary calcium excretion and calcium stone formation

- Allopurinol and newer febuxostat xanthine-oxidase inhibitors reduce uric acid excretion

- Various NSAID analgesics are the mainstay of symptomatic treatment of renal colic

- Effectiveness of medical expulsion therapy with alpha-blockers or calcium channel blockers is currently being debated

\section{Appendix - Preventive pharmacological therapies - urinary alkalinizers ${ }^{123}$}

Potassium Citrate $5 \mathrm{mEq}$

Potassium Citrate $10 \mathrm{mEq}$

Potassium Citrate $15 \mathrm{mEq}$

Potassium Citrate

Uro Cit K 5

Uro Cit K 10

Cytra-3 


\section{Cytra-K \\ Cytra-LC \\ Effer-K \\ K-Citra \\ Klor-con/EF}

Klor-vess

Polycitra-K

Polycitra-LC

Resol

Taron

Sorbutuss NR

Tricitrates Oral Solution USP 36,Tri-K

Twin K

Sodium Potassium Citrate

Potassium Magnesium Citrate

Calcium Citrate

7. References 
1. Romero V, Akpinar H, Assimos DG. Kidney stones: a global picture of prevalence, incidence, and associated risk factors. Rev Urol 2010;12(2-3):e86-96

2. Scales CD, Smith AC, Hanley JM, Saigal CS, Project UDiA. Prevalence of kidney stones in the United States. Eur Urol 2012 Jul;62(1):160-5

3. Stamatelou KK, Francis ME, Jones CA, Nyberg LM, Curhan GC. Time trends in reported prevalence of kidney stones in the United States: 1976-1994. Kidney Int 2003 May;63(5):1817-23

4. Ngo TC, Assimos DG. Uric Acid nephrolithiasis: recent progress and future directions. Rev Urol 2007;9(1):17-27.* Excellent review of uric acid metabolism and pathophysiology

5. Pearle MS, Goldfarb DS, Assimos DG, Curhan G, Denu-Ciocca CJ, Matlaga BR, et al. Medical management of kidney stones: AUA guideline. J Urol 2014 Aug;192(2):316-24. *A must read for any physician involved in management of renal stones. Summary of all key evidence and clear guidelines.

6. Laerum E, Larsen S. Thiazide prophylaxis of urolithiasis. A double-blind study in general practice. Acta Med Scand 1984;215(4):383-9

7. Arrabal-Martín M, Fernández-Rodríguez A, Arrabal-Polo MA, García-Ruiz MJ, Zuluaga-Gómez A. Extracorporeal renal lithotripsy: evolution of residual lithiasis treated with thiazides. Urology 2006 Nov;68(5):956-9

8. Yendt ER, Cohanim M. Prevention of calcium stones with thiazides. Kidney Int 1978 May;13(5):397-409.*An original article from the 1970's describing thiazide effects and common reactions.

9. Pak CY, Peterson R, Sakhaee K, Fuller C, Preminger G, Reisch J. Correction of hypocitraturia and prevention of stone formation by combined thiazide and potassium citrate therapy in thiazideunresponsive hypercalciuric nephrolithiasis. Am J Med 1985 Sep;79(3):284-8

10. Chlorothiazide | Drug Summary | PDR.net. 2015 [cited; Available from: http://www.pdr.net/drug-summary/chlorothiazide?druglabelid=1960

11. Amiloride Hydrochloride and Hydrochlorothiazide | Drug Summary | PDR.net. 2015 [cited; Available from: http://www.pdr.net/drug-summary/amiloride-hydrochloride-andhydrochlorothiazide?druglabelid=1785\&id $=2883$

12. Dyazide | Drug Summary | PDR.net. 2015 [cited; Available from: http://www.pdr.net/drugsummary/dyazide?druglabelid=184\&id=1091

13. ALLHAT Officers and Coordinators for the ALLHAT Collaborative Research Group. Major outcomes in moderately hypercholesterolemic, hypertensive patients randomized to pravastatin vs usual care: The Antihypertensive and Lipid-Lowering Treatment to Prevent Heart Attack Trial (ALLHATLLT). JAMA 2002 Dec;288(23):2998-3007

14. Arrow-Bendrofluazide | New Zealand Data Sheet | medsafe.govt.nz. 2015 [cited 06/14/2015]; Available from: http://www.medsafe.govt.nz/profs/datasheet/a/arrow-bendrofluazidetab.pdf

15. Ellison $\mathrm{DH}$, Loffing J. Thiazide effects and adverse effects: insights from molecular genetics. Hypertension 2009 Aug;54(2):196-202

16. Hydrochlorothiazide Tablets | Drug Summary | PDR.net. 2015 [cited 06/14/2015]; Available from: http://www.pdr.net/drug-summary/hydrochlorothiazide-tablets?druglabelid=1973\&id=1942

17. Ceylan K, Topal C, Erkoc R, Sayarlioglu H, Can S, Yilmaz Y, et al. Effect of indapamide on urinary calcium excretion in patients with and without urinary stone disease. Ann Pharmacother 2005 Jun;39(6):1034-8

18. Borghi L, Meschi T, Guerra A, Novarini A. Randomized prospective study of a nonthiazide diuretic, indapamide, in preventing calcium stone recurrences. J Cardiovasc Pharmacol 1993;22 Suppl 6:S78-86

19. Indapamide | Drug Summary | PDR.net. 2015 [cited 06/14/2015]; Available

from: http://www.pdr.net/drug-summary/indapamide?druglabelid=2292 
20. Amiloride Hydrochloride | Drug Summary | PDR.net. 2015 [cited 07/12/2015]; Available from: http://www.pdr.net/drug-summary/amiloride-hydrochloride?druglabelid=1840

21. Maschio G, Tessitore N, D'Angelo A, Fabris A, Pagano F, Tasca A, et al. Prevention of calcium nephrolithiasis with low-dose thiazide, amiloride and allopurinol. Am J Med 1981 Oct;71(4):623-6

22. Goldberg H, Grass L, VogI R, Rapoport A, Oreopoulos DG. Urine citrate and renal stone disease. CMAJ 1989 Aug;141(3):217-21.** Excellent review of citrate metabolism in the urine and its implications.

23. Pearle MS, Lotan Y. Urinary Lithiasis: Etiology, Epimiology and Pathogenesis. In: Wein AJ, Kavoussi LR, Novick AC, Partin AW, Peters CA, eds. Campbell-Walsh Urology. 10th Edition ed: Elsevier Saunders 2012:1257-86

24. Biasz S, Felix R, Newman W, et al. Quantitative determination of inhibitors of calcium phosphate precipitation in whole urine. Miner Electrolyte Metab 1978(1):74-83

25. Pak CY, Fuller C. Idiopathic hypocitraturic calcium-oxalate nephrolithiasis successfully treated with potassium citrate. Ann Intern Med 1986 Jan;104(1):33-7

26. Rudman D, Kutner MH, Redd SC, Waters WC, Gerron GG, Bleier J. Hypocitraturia in calcium nephrolithiasis. J Clin Endocrinol Metab 1982 Dec;55(6):1052-7

27. Urinary Alkalinization Medication | Drugs.com. 2015 [cited July 30 2015]; Available from: http://www.drugs.com/condition/urinary-alkalinization.html

28. Urocit-K | Drug Summary | PDR.net. 2015 [cited 2015 July 30]; Available from: http://www.pdr.net/drug-summary/urocit-k?druglabelid=414

29. RxMed: Pharmaceutical Information - POLYCITRA. 2015 [cited 30 July 2015]; Available from: http://www.rxmed.com/b.main/b2.pharmaceutical/b2.1.monographs/CPS-\%20Monographs/CPS\%20(General\%20Monographs-\%20P)/POLYCITRA.html

30. DailyMed - ORACIT- citric acid monohydrate and trisodium citrate dihydrate liquid. 2015 [cited July 30 2015]; Available from: http://dailymed.nlm.nih.gov/dailymed/druglnfo.cfm?setid=a8918fc4679e-41a9-8d0f-68436aed966b

31. Albrights Solution, Bicitra (sodium citrate/citric acid) dosing, indications, interactions, adverse effects, and more. 2015 [cited July 30 2015]; Available from: http://reference.medscape.com/drug/albrights-solution-cytra-2-sodium-citrate-citric-acid-342854

32. Muldowney FP, Freaney R, Moloney MF. Importance of dietary sodium in the hypercalciuria syndrome. Kidney Int 1982 Sep;22(3):292-6

33. Urocit-K | FULL Prescribing Information | PDR.net. 2015 [cited 06/14/2015]; Available from: http://www.pdr.net/full-prescribing-information/urocit-k?druglabelid=414

34. Potassium citrate tablets for nephrolithiasis. Med Lett Drugs Ther 1986 Apr;28(712):48

35. Ferrandino MN, Pietrow PK, Preminger GM. Evaluation and Medical Management of Urinary Lithiasis. In: Wein AJ, Kavoussi LR, Novick AC, Partin AW, Peters CA, eds. Campbell-Walsh Urology. 10th Edition ed: Elsevier Saunders 2012:1287-323

36. Sakhaee K, Poindexter JR, Griffith CS, Pak CY. Stone forming risk of calcium citrate supplementation in healthy postmenopausal women. J Urol 2004;172(3):958-61

37. Finkielstein VA, Goldfarb DS. Strategies for preventing calcium oxalate stones. CMAJ 2006 May;174(10):1407-9

38. Mandel NS, Mandel GS. Urinary tract stone disease in the United States veteran population. II. Geographical analysis of variations in composition. J Urol 1989 Dec;142(6):1516-21

39. Coe FL, Strauss AL, Tembe V, Le Dun S. Uric acid saturation in calcium nephrolithiasis. Kidney Int 1980 May;17(5):662-8

40. Pak CY, Sakhaee K, Peterson RD, Poindexter JR, Frawley WH. Biochemical profile of idiopathic uric acid nephrolithiasis. Kidney Int 2001 Aug;60(2):757-61 
41. Maalouf NM, Cameron MA, Moe OW, Sakhaee K. Novel insights into the pathogenesis of uric acid nephrolithiasis. Curr Opin Nephrol Hypertens 2004 Mar;13(2):181-9

42. Pacher $P$, Nivorozhkin A, Szabó $C$. Therapeutic effects of xanthine oxidase inhibitors: renaissance half a century after the discovery of allopurinol. Pharmacol Rev 2006 Mar;58(1):87-114

43. Zyloprim | Drug Summary | PDR.net. 2015 [cited 06/14/2015]; Available from: http://www.pdr.net/drug-summary/zyloprim?druglabelid=816\&id=988

44. Wortmann RL. Gout and hyperuricemia. Curr Opin Rheumatol 2002 May;14(3):281-6

45. Hande KR, Noone RM, Stone WJ. Severe allopurinol toxicity. Description and guidelines for prevention in patients with renal insufficiency. Am J Med 1984 Jan;76(1):47-56

46. Terkeltaub RA. Clinical practice. Gout. N Engl J Med 2003 Oct;349(17):1647-55

47. Becker MA, Schumacher HR, Wortmann RL, MacDonald PA, Eustace D, Palo WA, et al.

Febuxostat compared with allopurinol in patients with hyperuricemia and gout. N Engl J Med 2005 Dec;353(23):2450-61

48. Goldfarb DS, MacDonald PA, Gunawardhana L, Chefo S, McLean L. Randomized controlled trial of febuxostat versus allopurinol or placebo in individuals with higher urinary uric acid excretion and calcium stones. Clin J Am Soc Nephrol 2013 Nov;8(11):1960-7.** First new drug for hyperuricosuria treatment in decades. Important study reviewing its effects.

49. Uloric | FULL Prescribing Information | PDR.net. 2015 [cited 06/14/2015]; Available from: http://www.pdr.net/full-prescribing-information/uloric?druglabelid=563\#i4i section ID s6.1

50. Ng CS, Streem SB. Contemporary management of cystinuria. J Endourol 1999 Nov;13(9):647-51

51. Joly D, Rieu P, Méjean A, Gagnadoux MF, Daudon M, Jungers P. Treatment of cystinuria. Pediatr Nephrol 1999 Nov;13(9):945-50

52. Saravakos P, Kokkinou V, Giannatos E. Cystinuria: current diagnosis and management. Urology 2014 Apr;83(4):693-9

53. Thiola | FULL Prescribing Information | PDR.net. 2015 [cited 06/14/2015]; Available from: http://www.pdr.net/full-prescribing-information/thiola?druglabelid=3227

54. Pak CY, Fuller CJ. Assessment of cystine solubility in urine and of heterogeneous nucleation. J Urol 1983 May;129(5):1066-70

55. Pak CY, Fuller C, Sakhaee K, Zerwekh JE, Adams BV. Management of cystine nephrolithiasis with alpha-mercaptopropionylglycine. J Urol 1986 Nov;136(5):1003-8

56. Cuprimine | Drug Summary | PDR.net. 2015 [cited; Available from: http://www.pdr.net/drugsummary/cuprimine?druglabelid $=1452 \&$ id $=630$

57. Andonopoulos AP, Terzis E, Tsibri E, Papasteriades CA, Papapetropoulos T. D-penicillamine induced myasthenia gravis in rheumatoid arthritis: an unpredictable common occurrence? Clin Rheumatol 1994 Dec;13(4):586-8

58. Sloand JA, Izzo JL. Captopril reduces urinary cystine excretion in cystinuria. Arch Intern Med 1987 Aug;147(8):1409-12

59. Perazella MA, Buller GK. Successful treatment of cystinuria with captopril. Am J Kidney Dis 1993 May;21(5):504-7

60. Barbey F, Joly D, Rieu P, Méjean A, Daudon M, Jungers P. Medical treatment of cystinuria: critical reappraisal of long-term results. J Urol 2000 May;163(5):1419-23

61. Dahlberg PJ, Jones JD. Cystinuria: failure of captopril to reduce cystine excretion. Arch Intern Med 1989 Mar;149(3):713, 17

62. du Toit PJ, van Aswegen CH, Nel JA, Steyn PL, Ligthelm AJ, du Plessis DJ. In vivo effects of ureaseproducing bacteria involved with the pathogenesis of infection-induced urolithiasis on renal urokinase and sialidase activity. Urol Res 1995;23(5):335-8 
63. Griffith DP, Bruce RR, Fishbein WN. Adapted from: Infection (urease)-induced stones. In: Coe FL, Brenner BM, Stein JH, eds. Nephrolithiasis, Contemporary Issues in Nephrology. New York: Churchill Livingstone 1980:231-60

64. Griffith DP, Gibson JR, Clinton CW, Musher DM. Acetohydroxamic acid: clinical studies of a urease inhibitor in patients with staghorn renal calculi. J Urol 1978 Jan;119(1):9-15

65. Lithostat | FULL Prescribing Information | PDR.net. 2015 [cited 06/14/2015]; Available from: http://www.pdr.net/full-prescribing-information/lithostat?druglabelid=3224

66. ACETOHYDROXAMIC ACID - National Library of Medicine HSDB Database. 2015 [cited 06/14/2015]; Available from: http://www.ncbi.nlm.nih.gov/pubmed/

67. Botting RM. Mechanism of action of acetaminophen: is there a cyclooxygenase 3 ? Clin Infect Dis 2000 Oct;31 Suppl 5:S202-10

68. Serinken M, Eken C, Turkcuer I, Elicabuk H, Uyanik E, Schultz $\mathrm{CH}$. Intravenous paracetamol versus morphine for renal colic in the emergency department: a randomised double-blind controlled trial. Emerg Med J 2012 Nov;29(11):902-5

69. Bektas F, Eken C, Karadeniz O, Goksu E, Cubuk M, Cete Y. Intravenous paracetamol or morphine for the treatment of renal colic: a randomized, placebo-controlled trial. Ann Emerg Med 2009 Oct;54(4):568-74

70. Extra Strength Tylenol Cold Sore Throat Liquid | Drug Summary | PDR.net. 2015 [cited 06/14/2015]; Available from: http://www.pdr.net/drug-summary/extra-strength-tylenol-cold-sorethroat-liquid?druglabelid=3253\&id=1501

71. Paracetamol | Data Sheet | medsafe.govt.nz. 2015 [cited 06/14/2015]; Available from: http://www.medsafe.govt.nz/profs/datasheet/p/panadoltab.pdf

72. Routledge P, Vale JA, Bateman DN, Johnston GD, Jones A, Judd A, et al. Paracetamol (acetaminophen) poisoning. No need to change current guidelines to accident departments. BMJ 1998 Dec;317(7173):1609-10

73. Botting RM. Inhibitors of cyclooxygenases: mechanisms, selectivity and uses. J Physiol Pharmacol 2006 Nov;57 Suppl 5:113-24

74. Holdgate A, Pollock T. Systematic review of the relative efficacy of non-steroidal antiinflammatory drugs and opioids in the treatment of acute renal colic. BMJ 2004;328(7453):1401

75. Afshar K, Jafari S, Marks AJ, Eftekhari A, MacNeily AE. Nonsteroidal anti-inflammatory drugs (NSAIDs) and non-opioids for acute renal colic. The Cochrane database of systematic reviews 2015;6:Cd006027

76. Opgenorth TJ, Fiksen-Olsen MJ, Romero JC. Role of prostaglandins in the cortical distribution of renal blood flow following reductions in renal perfusion pressure. Prostaglandins 1987 Oct;34(4):591602

77. Whelton A, Hamilton CW. Nonsteroidal anti-inflammatory drugs: effects on kidney function. J Clin Pharmacol 1991 Jul;31(7):588-98

78. Voltaren XR | Drug Summary | PDR.net. 2015 [cited 06/14/2015]; Available from: http://www.pdr.net/drug-summary/voltaren-xr?druglabelid=2033\&id=756

79. Lanza FL, Chan FK, Quigley EM, Gastroenterology PPCotACo. Guidelines for prevention of NSAIDrelated ulcer complications. Am J Gastroenterol 2009 Mar;104(3):728-38

80. Becker JC, Domschke W, Pohle T. Current approaches to prevent NSAID-induced gastropathy-COX selectivity and beyond. Br J Clin Pharmacol 2004 Dec;58(6):587-600

81. Toepfer NJ, Baylor K, Henry Y, Simmons J, Berger PB. The effect of antiplatelet and anticoagulant therapy on the clinical outcome of patients undergoing ureteroscopy. Urology 2013 Oct;82(4):773-9 82. Lennon GM, Bourke J, Ryan PC, Fitzpatrick JM. Pharmacological options for the treatment of acute ureteric colic. An in vitro experimental study. Br J Urol 1993 Apr;71(4):401-7 
83. Cordell WH ea. Comparison of intravenous ketorolac, meperidine, and both (balanced analgesia) for renal colic. - PubMed - NCBI. 2015

84. Ketorolac Tromethamine Tablets | Drug Summary | PDR.net. 2015 [cited; Available from: http://www.pdr.net/drug-summary/ketorolac-tromethamine-tablets?druglabelid=1793\&id=2273

85. Bombardier C, Laine L, Reicin A, Shapiro D, Burgos-Vargas R, Davis B, et al. Comparison of upper gastrointestinal toxicity of rofecoxib and naproxen in patients with rheumatoid arthritis. VIGOR Study Group. N Engl J Med 2000 Nov;343(21):1520-8, 2 p following 28. ** Important study pointing out increased cardiovascular risks with COX-2 inhibitors.

86. Celebrex | Drug Summary | PDR.net. 2015 [cited 06/14/2015]; Available from: http://www.pdr.net/drug-summary/celebrex?druglabelid=532\&id=928

87. Nakada SY, Jerde TJ, Bjorling DE, Saban R. Selective cyclooxygenase-2 inhibitors reduce ureteral contraction in vitro: a better alternative for renal colic? J Urol 2000 Feb;163(2):607-12

88. Bovill JG. Mechanisms of actions of opioids and non-steroidal anti-inflammatory drugs. Eur J Anaesthesiol Suppl 1997 May;15:9-15

89. Candiotti KA, Gitlin MC. Review of the effect of opioid-related side effects on the undertreatment of moderate to severe chronic non-cancer pain: tapentadol, a step toward a solution? Curr Med Res Opin 2010 Jul;26(7):1677-84

90. Avinza | Drug Summary | PDR.net. 2015 [cited; Available from: http://www.pdr.net/drugsummary/avinza?druglabelid $=2277 \&$ id $=781$

91. Ballantyne JC, Mao J. Opioid therapy for chronic pain. N Engl J Med 2003 Nov;349(20):1943-53

92. Paronis CA, Holtzman SG. Development of tolerance to the analgesic activity of mu agonists after continuous infusion of morphine, meperidine or fentanyl in rats. J Pharmacol Exp Ther 1992 Jul;262(1):1-9

93. Latta KS, Ginsberg B, Barkin RL. Meperidine: a critical review. Am J Ther 20022002 JanFeb;9(1):53-68

94. Weiner AL. Meperidine as a potential cause of serotonin syndrome in the emergency department. Academic emergency medicine : official journal of the Society for Academic Emergency Medicine 1999 Feb;6(2):156-8

95. Raffa RB, Friderichs E, Reimann W, Shank RP, Codd EE, Vaught JL. Opioid and nonopioid components independently contribute to the mechanism of action of tramadol, an 'atypical' opioid analgesic. J Pharmacol Exp Ther 1992 Jan;260(1):275-85

96. Hazhir S, Badr YA, Darabi JN. Comparison of intranasal desmopressin and intramuscular tramadol versus pethidine in patients with renal colic. Urology journal 2010;7(3):148-51

97. Ultram | Drug Summary | PDR.net. 2015 [cited 06/14/2015]; Available from: http://www.pdr.net/drug-summary/ultram?druglabelid=950\&id=904

98. Mahlberg R, Kunz D, Sasse J, Kirchheiner J. Serotonin syndrome with tramadol and citalopram. Am J Psychiatry 2004 Jun;161(6):1129

99. Iqbal MM, Basil MJ, Kaplan J, Iqbal MT. Overview of serotonin syndrome. Ann Clin Psychiatry 2012 Nov;24(4):310-8

100. Miyaoka R, Monga M. Ureteral stent discomfort: Etiology and management. Indian J Urol 2009 2009 Oct-Dec;25(4):455-60

101. Pyridium | Drug Summary | PDR.net. 2015 [cited; Available from: http://www.pdr.net/drugsummary/pyridium?druglabelid $=3457$

102. Malin JM, Deane RF, Boyarsky S. Characterisation of adrenergic receptors in human ureter. $\mathrm{Br} J$ Urol 1970 Apr;42(2):171-4

103. Lipkin $M$, Shah $O$. The use of alpha-blockers for the treatment of nephrolithiasis. Rev Urol 2006;8 Suppl 4:S35-42.**Excellent, clear review of the subject. 
104. Lamb AD, Vowler SL, Johnston R, Dunn N, Wiseman OJ. Meta-analysis showing the beneficial effect of $\alpha$-blockers on ureteric stent discomfort. BJU Int 2011 Dec;108(11):1894-902

105. Lepor H. Alpha blockers for the treatment of benign prostatic hyperplasia. Rev Urol 2007;9(4):181-90

106. Richardson CD, Donatucci CF, Page SO, Wilson KH, Schwinn DA. Pharmacology of tamsulosin: saturation-binding isotherms and competition analysis using cloned alpha 1-adrenergic receptor subtypes. Prostate 1997 Sep;33(1):55-9

107. Sigala S, Dellabella M, Milanese G, Fornari S, Faccoli S, Palazzolo F, et al. Evidence for the presence of alpha1 adrenoceptor subtypes in the human ureter. Neurourol Urodyn 2005;24(2):142-8

108. De Sio M, Autorino R, Di Lorenzo G, Damiano R, Giordano D, Cosentino L, et al. Medical expulsive treatment of distal-ureteral stones using tamsulosin: a single-center experience. J Endourol 2006 Jan;20(1):12-6

109. Pickard R, Starr K, MacLennan G, Lam T, Thomas R, Burr J, et al. Medical expulsive therapy in adults with ureteric colic: a multicentre, randomised, placebo-controlled trial. Lancet 2015 May. ${ }^{* *}$ Freshoff-the-press new trial demonstrating ineffectiveness of MET

110. Hellstrom WJ, Sikka SC. Effects of acute treatment with tamsulosin versus alfuzosin on ejaculatory function in normal volunteers. J Urol 2006 Oct;176(4 Pt 1):1529-33

111. Committee APG. AUA guideline on management of benign prostatic hyperplasia (2003). Chapter 1: Diagnosis and treatment recommendations. J Urol 2003 Aug;170(2 Pt 1):530-47

112. Nazim SM, Ather MH. Alpha-blockers impact stent-related symptoms: a randomized, doubleblind, placebo-controlled trial. J Endourol 2012 Sep;26(9):1237-41

113. Seitz C, Liatsikos E, Porpiglia F, Tiselius HG, Zwergel U. Medical therapy to facilitate the passage of stones: what is the evidence? Eur Urol 2009 Sep;56(3):455-71.** Meta-analysis of MET with clear presentation of results.

114. Dellabella M, Milanese G, Muzzonigro G. Randomized trial of the efficacy of tamsulosin, nifedipine and phloroglucinol in medical expulsive therapy for distal ureteral calculi. J Urol 2005 Jul;174(1):167-72

115. Dellabella M, Milanese G, Muzzonigro G. Medical-expulsive therapy for distal ureterolithiasis: randomized prospective study on role of corticosteroids used in combination with tamsulosin-simplified treatment regimen and health-related quality of life. Urology 2005 Oct;66(4):712-5

116. Mukamel E, Engelstein D, Simon D, Servadio C. The value of Rowatinex in the treatment of ureterolithiasis. J Urol (Paris) 1987;93(1):31-3

117. Romics I, Siller G, Kohnen R, Mavrogenis S, Varga J, Holman E. A special terpene combination (Rowatine ${ }^{\circledR}$ ) improves stone clearance after extracorporeal shockwave lithotripsy in urolithiasis patients: results of a placebo-controlled randomised controlled trial. Urol Int 2011;86(1):102-9

118. Djaladat H, Mahouri K, Khalifeh Shooshtary F, Ahmadieh A. Effect of Rowatinex on calculus clearance after extracorporeal shock wave lithotripsy. Urology journal 2009;6(1):9-13

119. Aldemir M, Uçgül YE, Kayıgil O. Evaluation of the efficiency of tamsulosin and Rowatinex in patients with distal ureteral stones: a prospective, randomized, controlled study. Int Urol Nephrol 2011 Mar;43(1):79-83

120. Troxel SA, Jones AW, Magliola L, Benson JS. Physiologic effect of nifedipine and tamsulosin on contractility of distal ureter. J Endourol 2006 Aug;20(8):565-8

121. Nifedipine | Drug Summary | PDR.net. 2015 [cited 06/14/2015]; Available from: http://www.pdr.net/drug-summary/nifedipine?druglabelid=1481\&id=932

122. ALLN-177 drug information. 2015 [cited 06/14/2015]; Available from: http://www.allenapharma.com/therapeutic-approach-ALLN.php

123. Dauw C. Preventive pharmacological therapies. Personal communication. 2015 


\section{Declaration of interest}

Nadya York, M.D. - no conflict of interest declared.

Michael S. Borofsky, M.D. - no conflict of interest declared.

James E. Lingeman, M.D. - no conflict of interest declared. 